\title{
Tumor Immunoediting, from T Cell-Mediated Immune Surveillance to Tumor-Escape of Uterine Leiomyosarcoma
}

Takuma Hayashi'10*, Akiko Horiuchi ${ }^{2,11}$, Kenji Sano ${ }^{3}$, Nobuyoshi Hiraoka ${ }^{4}$, Tomoyuki Ichimura ${ }^{5}$, Osamu Ishiko ${ }^{5}$, Yae Kanai ${ }^{4}$, Nobuo Yaegashi $^{6}$, Hiroyuki Aburatani ${ }^{7}$, Tanri Shiozawa ${ }^{2}$, Susumu Tonegawa ${ }^{8}$ and Ikuo Konishi ${ }^{9}$

${ }^{1}$ Department of Immunology and Infectious Disease, Shinshu University Graduate School of Medicine, Japan

${ }^{2}$ Department of Obstetrics and Gynecology, Shinshu University School of Medicine, Japan

${ }^{3}$ Department of Laboratory Medicine, Shinshu University Hospital, Japan

${ }^{4}$ Pathology Division, National Cancer Center Research Institute, Japan

${ }^{5}$ Department of Obstetrics and Gynecology, Osaka City University Graduate School of Medicine, Japan

${ }^{6}$ Department of Obstetrics and Gynecology, Tohoku University Graduate School of Medicine, Japan

${ }^{7}$ The Cancer System Laboratory, Research Center for Advanced Science and Technology, The University of Tokyo, Japan

${ }^{8}$ Picower Institute and Department of Biology, Massachusetts Institute of Technology, USA

${ }^{9}$ Department of Obstetrics and Gynecology, Kyoto University Graduate School of Medicine, Japan

${ }^{10}$ Promoting Business using Advanced Technology, Japan Science and Technology Agency (JST), Japan

${ }^{11}$ Department of Obstetrics and Gynecology, Aizawa Hospital, Japan

\begin{abstract}
The majority of smooth muscle tumors found in the uterus are benign, but uterine leiomyosarcomas (LMSs) are extremely malignant, with high rates of recurrence and metastasis. The development of gynecologic tumors is often correlated with female hormone secretion; however, the development of uterine LMS is not substantially correlated with hormonal conditions, and the risk factors are not clearly understood. The presentation of antigenic peptides by major histocompatibility complex (MHC) class I molecules is important for tumor rejection by cytotoxic T-lymphocytes (CTLs). Such antigenic peptides are generated as a result of the degradation of intracellular proteins by the proteasome pathway, a process that is by the interferon (IFN)- - -inducible low molecular mass polypeptide-2 (LMP2) subunit of the 20S proteasome. Homozygous mice for LMP2 are now known to spontaneously develop uterine LMS. LMP2 expression is reportedly absent in human uterine LMS, but present in human myometrium. Further studies revealed a few $\quad$ CD56 ${ }^{+}$NK cells in human uterine LMS tissues. This review aims at summarizing recent insights into the regulation of NK cell function and the T cell-mediated immune
\end{abstract}

Keywords: LMP2; Uterine leiomyosarcoma; T Cell-mediated immunity; Natural killer cells

\section{Introduction}

The uterus, the organ in which the embryo grows, is composed of three layers, the uterine endometrium, the myometrium composed of smooth muscle and a serious membrane enveloping the uterus. In general, the term uterine tumor refers to an epithelial malignant tumor of the uterus, which is roughly classified as a tumor of the uterine cervix or the uterine body. Because of the prevalence of screening, uterine cervix cancer is decreasing in incidence, and usually detected at an early stage. In contrast, cancer of the uterine body is increasing in incidence, and rarely detected at the initial stages. While most tumors of the uterine body are adenocarcinomas derived from the subintimal gland, tumors of the uterine cervix are classified into squamous cancer and adenocarcinoma. Smooth muscle tumors (SMTs) which develop in the myometrium have been traditionally divided into benign leiomyoma (LMA) and malignant leiomyosarcoma (LMS) based on cytological atypia, mitotic activity and other criteria. Uterine LMS is a rare gynecologic malignancy in the female genital tract, having an estimated annual incidence of 0.64 per 100,000 women [1]. Uterine LMS accounts for $2 \%$ to $5 \%$ of tumors of the uterine body and develops more often in the muscle layer of the uterine body than in the uterine cervix $[2,3]$.

A main factor in the development of tumors in the uterine body is the hormonal environment. Patients with uterine body tumors often are unmarried, have never been pregnant, and are taking a hormonal agent. High estrogen levels are considered to significantly influence the development of such tumors. The mechanisms by which uterine LMA and LMS develop are not yet clearly understood, though tumors that have developed in the myometrium for some reason gradually become larger due to the influence of the female hormone, estrogen, and generate tumors. However, no correlations between the development of uterine LMS and hormonal conditions, and no obvious risk factors have been identified. The prognosis of uterine LMS is not good, and the five-year survival rate is approximately $35 \%$, although the five-year survival rate depends on disease stage [2,3]. It is worth noting that, when adjusted for stage and mitotic count, LMS has a significantly worse prognosis than carcinosarcoma [4]. As uterine LMS is resistant to chemotherapy and radiotherapy, and thus surgical intervention is virtually the only means of treatment, developing an efficient adjuvant therapy is expected to improve the prognosis of the disease [5-7]. Most damaged cells can initiate tumor. To avert this, faulty cells disable their own propagation by undergoing senescence. Fortunately, cells

*Corresponding author: Takuma Hayashi, Department of Immunology and Infectious Disease, Shinshu University Graduate School of Medicine, 3-1-1, Asahi, Matsumoto, Nagano 390-8621, Japan, Tel: 81-263-37-2611; Fax: 81-263-37-2613; E-mail: takumah@shinshu-u.ac.jp

Received October 21, 2011; Accepted February 24, 2012; Published February 28, 2012

Citation: Hayashi T, Horiuchi A, Sano K, Hiraoka N, Ichimura T, et al. (2012) Tumor Immunoediting, from T Cell-Mediated Immune Surveillance to Tumor-Escape of Uterine Leiomyosarcoma. J Vaccines Vaccin S1:002. doi:10.4172/2157-7560.S1002

Copyright: ( 2012 Hayashi T, et al. This is an open-access article distributed under the terms of the Creative Commons Attribution License, which permits unrestricted use, distribution, and reproduction in any medium, provided the original author and source are credited. 
can detect their own level of damage and eventually dismiss themselves in a final act of altruism for the benefit of the organism. Self-dismissal comes in two forms, apoptosis "self-destruction" and senescence "selfdisabling", with the latter being at least as prominent as the former in providing protection against malignant tumors [8,9]. But for full protection against malignant tumors, the senescent cells must be cleared by the T cell-mediated immune system including NK cells $[10,11]$. The biological characteristic of uterine LMS would significantly contribute to the development of preventive and therapeutic treatments.

\section{Proteasomal Function Induced by IFN- $\gamma$ in MHC Class I-Mediated Tumor Rejection}

When tissue or an organ is transplanted, the arograft is often lost due to an acute rejection caused by the host immune-system. This is because the cell surface antigens presented by the major histocompatibility complex (MHC) are intrinsic to an individual and so differ between the donor and recipient. The immunological self-markers on cell surfaces are the most important immune-system for higher vertebrates such as mammals, protecting the self from invaders. Cytoplasmic proteins are mostly degraded by a protease complex, which has many substrates consisting of twenty-eight 20 to $30-\mathrm{kDa}$ subunits, referred as the proteasome [12]. The proteasomal degradation pathway is essential for many cellular processes, including the cell cycle and the regulation of gene expression. Proteasomal degradation pathway is also essential for the production of peptide antigens, which are presented by $\mathrm{MHC}$ class I molecules. The proteasome plays a key role in the presentation of immunological self-markers on the cell surface by the MHC [12]. IFN- $\gamma$ up-regulates the expression of large numbers of responsive genes, proteasome's subunits, i.e., low-molecular mass polypeptide (LMP) 2, LMP7, and LMP10 are also markedly induced by IFN- $\gamma$ [13$16]$.

The IFN- $\gamma$-induced biological function of a reconstructive proteasome, called the immuno-proteasome, plays a key role in $\mathrm{MHC}$ class I-mediated tumor rejection [15,17]. Furthermore, a molecular approach to studying the correlation of IFN- $\gamma$ with tumor cell growth has drawn attention. A deficiency of IFN- $\gamma$ apparently does not hamper the generation of cytotoxic T lymphocyte (CTL) [14,15]. Recent reports have demonstrated multifunctional deficiencies of components of the MHC class I antigen-presentation pathway including LMP2 and LMP7 in tumor cells $[15,17]$. Here we identify LMP2, a single IFN- $\gamma$ responsive gene product, as obligatory for tumor surveillance [16].

\section{Defective LMP2 Expression in Uterine LMS}

Malignant tumors originate from a single cancerous cell and develop as a result of unlimited cell proliferation. Malignant tumor cells have properties that are biologically different from those of normal cells, thus, the host immune-system should be able to distinguish malignant tumor cells from corresponding normal cells. That is, malignant tumor cells present intrinsic antigens as tumor-antigens (TA) on the tumor cell surface with the aid of MHC molecules. In many cases, however, almost no reaction by the immune-system is observed. Also, the incidence of major tumors is not very different between immunodeficient (i.e., lymphocyte-deficient) mice and control mice having normal immunesystems. Specifically, tumor cells can avoid the immune monitoring system via several means $[10,11,18,19]$. Naturally- occurring tumor cells seem to have lost the expression of peptide antigens, TA, or celladhesion factors intrinsic to tumors. Tumor cells may avoid the host immune reaction due to the absence of MHC expression, although no such mechanism has yet been completely elucidated.
The genes encoding LMP2, LMP7, TAP1 and TAP2, are located in the region encoding the MHC molecules. The homozygous deficient mice for LMP2 show tissue- and substrate- dependent abnormalities in the biological functions of the proteasome, and impaired functioning of the proteasome in splenocytes or hepatic cells [20]. Furthermore, LMP2-deficient mice do not show normal immune responses to virusinfected cells, and such immunopathy is known to result from a failure in the presentation of peptide antigens on the cell surface by the MHC [20]. Uterine LMS reportedly occurred in female LMP2-deficient mice at age 6 months or older, and the incidence at 14 months of age was about $40 \%[21,22]$. The curve indicating the incidence in mice is very similar to that indicating the incidence of human uterine LMS, which occurs after menopause. Histological studies of LMP2-lacking uterine tumors revealed characteristic abnormalities of uterine LMS [21,22]. The tumors lacked lymphoid infiltrates, a sign of immune recognition, and consisted of uniform elongated myometrium cells arranged into bundles. The nuclei of the tumor cells varied in size and shape, furthermore, mitosis was frequent, in contrast, the myometrium cells of C57BL/6 mice were normal in appearance $[21,22]$. Whereas relatively few Ki-67-positive cells, the proliferating cells of solid tumors, were observed in the basal cell layer of the normal myometrium, most of the basal cells vividly expressed Ki-67 in LMP2-deficient mice [21,22].

LMP2-deficient mice that have developed uterine LMS undergo considerable weight loss, and then die by 14 months of age [21]. The LMP2-deficient mice also exhibit skeletal muscle metastasis from uterine LMS. Therefore it is likely that LMP2-deficient mice with uterine LMS died from the mass effect and metastasis. In general, it is not easy to distinguish uterine LMA from LMS. However, in mice, because of such characteristic pathological findings, significant weight loss and skeletal muscle metastasis, a tumor that develops in the uterus of an LMP2-deficient mouse can be considered malignant, i.e., a uterine LMS. Further experiments demonstrated the loss of LMP2 expression in human LMS, but detectable LMP2 expression in human LMA $[22,23]$. Therefore defective LMP2 expression is likely to be one of the risk factors for the development of human uterine neoplasm, as it is in the LMP2-deficient mouse [21-23].

\section{Impaired Tumor-Rejection to Uterine LMS by CTLs}

Spontaneously arising tumors are rarely rejected by CTLs [24]. It is probable that they lack either distinctive antigenic peptides or the adhesion and costimulatory molecules necessary to elicit primary $\mathrm{T}$ cell-responses. Tumors tend to be genetically unstable and can lose their antigens by mutation so that in the event of an immune response, more escape mutants might be generated [25]. Several research reports indicate functional deficiencies of components of the MHC class I antigen pathway, including LMP2 in individual tumor cells [26-29]. Recent findings also support a reciprocal and linked derangement in the immune response to tumor development [30-33] For instance, IFN- $\gamma$-insensitive mice that lack either the IFN $-\gamma$ receptor or Stat 1 were tested for the role of immune surveillance in tumor cell progression [31]. These mice lack the IFN- $\gamma$ signaling pathway that induces antigenic peptide presentation with MHC class I. Indeed, the incidence of chemical carcinogen-induced cancer was clearly higher in both types of mice than in normal mice [31].

The current studies support the idea that LMP2 may also be important for cancer target recognition. In this study, LMP2-deficient mice revealed that this proteasomal subunit significantly influences antigen processing for MHC class I molecule-binding peptides, and LMP2-deficient mice have reduced levels of immunological competency 
Citation: Hayashi T, Horiuchi A, Sano K, Hiraoka N, Ichimura T, et al. (2012) Tumor Immunoediting, from T Cell-Mediated Immune Surveillance to Tumor-Escape of Uterine Leiomyosarcoma. J Vaccines Vaccin S1:002. doi:10.4172/2157-7560.S1-002

by CTLs [34]. The defective antigen presentation associated with LMP2-deficiency may therefore promote direct escape from immune recognition by CTLs.

\section{Uterine-Specific Features of Natural Killer (NK) Cells}

NK cells are lymphocytes of the innate immune system that are able to kill various hazardous pathogens and tumors. However, it is now widely accepted that NK cells also possess non-destructive functions, as has been demonstrated for uterine NK cells. NK cells comprise approximately $5-15 \%$ of peripheral blood lymphocytes. They originate in the bone marrow from $\mathrm{CD} 34^{+}$hematopoietic progenitor cells, although recent studies suggest that NK cell development also occurs in secondary lymphoid tissues and in the thymus [35-37]. NK cells populate different peripheral lymphoid and non-lymphoid organs, including lymph nodes, thymus, tonsils, spleen, and uterus $[37,38]$. These innate effecter cells specialize in killing tumor and virally infected cells and are able to secrete a variety of cytokines $[39,40]$. The CD56 ${ }^{\text {dim }} \mathrm{CD} 16^{+} \mathrm{NK}$ cells, which comprise $90 \%$ of the NK population, are considered to be more cytotoxic than the CD56 ${ }^{\text {bright }}$ CD16 NK cells, which comprise only $10 \%$ of peripheral blood NK cells and are the primary source of NK-derived immunoregulatory chemo- and cytokines, such as IFN- $\gamma$ and CXCL8 [41] (Table 1).

The CD56 bright $\mathrm{CD} 16$ NK cells are considered as the regulatory subset and a prominent example of their regulatory role is in the uterine mucosa prior to and during pregnancy in the endometrial and decidual tissues, respectively (Table 1). Information on receptor/ ligand systems used by NK cells to specifically detect tumor cells has been accumulating rapidly. One of these receptor/ligand systems, the NKG2D pathway, has received particular attention, and now serves as a paradigm for how the immune system is able to gather information about the health status of autologous host cells. It is known that certain cytokines, for instance IL-21 and IFN- $\alpha$ exert anti-tumor effects raising the possibility that some of the beneficial effects are mediated by NKG2D.

In general, in the case of solid malignant tumors, although infiltrating lymphocytes can possibly be detected in small tumors or pre-malignant tumors at the earliest stage, they are not easy to detect in large growing tumors including malignant tumors. In the case of uterine LMS, the pathological findings are similar to those for uterine LMA or other malignant tumors. The tumor cells then become a premalignant tumor or senescent mass and are swiftly and selectively eliminated by immune cells - a fate delivered mainly by the innate arm of the immune system (macrophages, neutrophils and natural killer cells). Pathological studies have demonstrated immune infiltration by $\mathrm{CD}^{2} 6^{+}$natural killer (NK) cells, $\mathrm{CD} 163^{+}$macrophages and $\mathrm{CD} 4^{+}$ or $\mathrm{CD}^{+} \mathrm{T}$ cells. Although LMS usually lacks lymphoid infiltrates recognizable on routine histological staining, furthermore histological examination revealed a few infiltrating $\mathrm{CD}_{5} 6^{+} \mathrm{NK}$ cells in human uterine LMS tissues (Figure 1).

Pre-malignant senescent cells secrete chemo- and cytokines and are subject to immune-mediated clearance (designated as 'senescence surveillance') which depends on an intact $\mathrm{T}$ cell-mediated adaptive immune response $[10,11]$. Therefore impaired immune surveillance of

\begin{tabular}{|c|c|c|c|}
\hline \multicolumn{4}{|c|}{ Cell features and functions } \\
\hline Receptor expression & Cytotoxicity and proliferation & $\begin{array}{l}\text { Effect or } \\
\text { molecule expression }\end{array}$ & Other function \\
\hline $\begin{array}{l}\text { CD3- CD122+ }{ }^{+} \text {LY49+, CD16- CD56 }{ }^{\mathrm{Hi}} \text {, CD94 (Hs); } \\
\mathrm{NKp}^{+}(\mathrm{Hs} / \mathrm{Mm}) ; \mathrm{NK} 1.1^{+}, \mathrm{NK} 1.2^{+} \text {and DX5 }(\mathrm{Mm})\end{array}$ & $\begin{array}{l}\text { CXCL } 8 \text { and CXCL12 }{ }^{\mathrm{Hi}}(\mathrm{Hs}) \text {; IF } \mathrm{N}-\mathrm{\gamma}, \\
\text { VEGF-A, VEGF-B and PLGE }{ }^{\mathrm{Hi}}(\mathrm{Mm})\end{array}$ & $\begin{array}{l}\text { ADCC and cytotoxicty } \\
\text { decreased (Hs) }\end{array}$ & $\begin{array}{l}\text { Regulate endometrial remodelling, angiogenesis } \\
\text { and implantation }(\mathrm{Hs} / \mathrm{Mm}) \text {; uterine NK cell-derrived }\end{array}$ \\
\hline
\end{tabular}

ADCC, antibody-dependent cell-mediated cytotoxicity; CXCL, CXC-chemokine ligand; DC, dendric cell; IFN-y, Interferon- $y$; NK, natural killer; PLGF, placental growth factor; VEGF-A, vascular endothelial growth factor-A; Hs, indicates evidence found in humans, $\mathrm{Mm}$, indicates evidence found in mice, and Hs/Mm, indicates evidence found in both human and mice

Table 1: Unique features of NK cells in Uterus [48-53]

IHC: Human Uterine Leiomyosarcoma

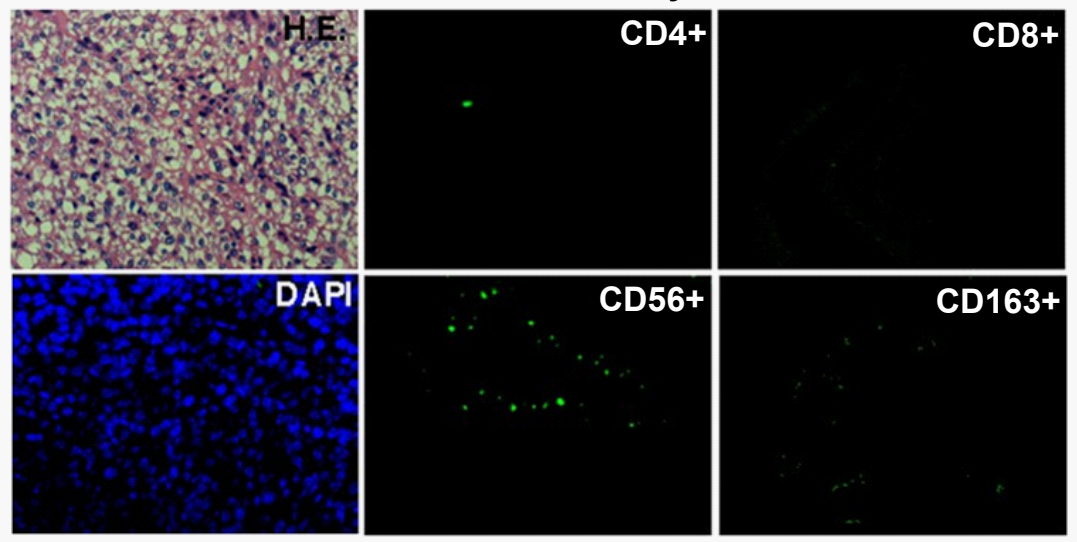

Figure 1:

The immunohistochemistry was performed to demonstrate the

$\mathrm{CD} 6^{+}$natural killer (NK) cells and $\mathrm{CD} 163^{+}$macrophages; CD4 ${ }^{+} \mathrm{T}$ cells or $\mathrm{CD} 8^{+} \mathrm{T}$ cells Although LMS usually lacks lymphoid recognizable on routine histological staining; further histological examination revealed a few

CD56 + NK cells in human uterine leiomyosarcoma tissues. 
Citation: Hayashi T, Horiuchi A, Sano K, Hiraoka N, Ichimura T, et al. (2012) Tumor Immunoediting, from T Cell-Mediated Immune Surveillance to Tumor-Escape of Uterine Leiomyosarcoma. J Vaccines Vaccin S1:002. doi:10.4172/2157-7560.S1-002

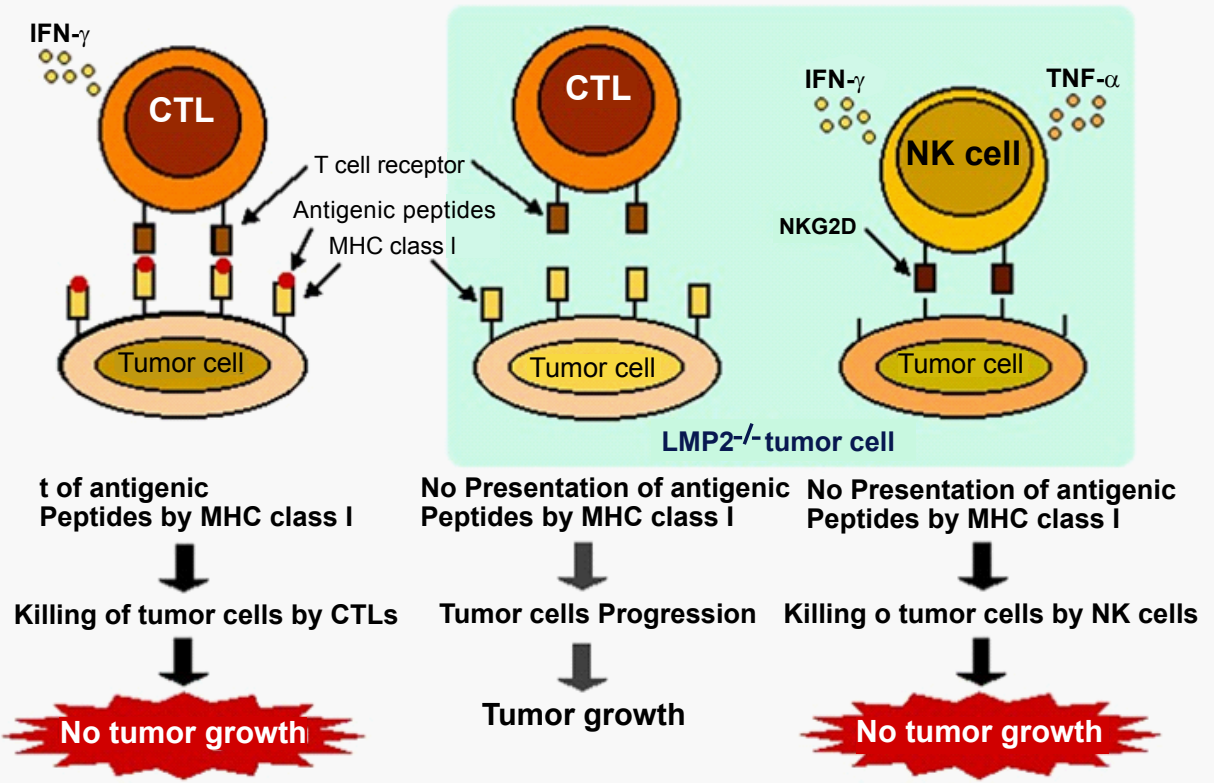

Figure 2: Model for the escape of LMP2 $2^{-/}$cancer cells from immune surveillance by CTLs and/or NK cells.

Tumor cells of wild-type mice express antigenic peptides derived from novel proteins on the cell surface in association with MHC class I molecules. These cells are therefore recognized and killed by CTLs and tumors do not progress. In contrast; the presentation of antigenic peptides and/or MHC class I molecules is impaired in $\mathrm{LMP}^{-/}$tumor cells as a result of a defect in proteasomal function. These LMP2/- tumor cells are therefore not attacked by CTLs, but may be recognized and killed by NK cells.

pre-malignant senescent cells results in the development of a malignant tumor or carcinomas, thus showing that senescence surveillance is important for tumor suppression. Recent study has shown that innate immune cells alone are sufficient to mediate the clearance of malignant tumors, wherein senescence was triggered by the reactivation of endogenous p53 [42]. Although research has demonstrated that the abnormal expression of ovarian steroid receptors, p53, Ki-67, mutations of p53 and cell cycle regulators including senescence markers are frequently associated with uterine LMS, clear scientific evidence of the characteristic secretion of chemo- and cytokines from uterine LMS is not available $[22,43,44]$. Furthermore the few infiltrating $\mathrm{CD} 56^{+} \mathrm{NK}$ cells might be attributable to functional deficiencies of the MHC class I antigen pathway in human uterine LMS tissues.

\section{Conclusion}

LMP2 is reportedly implicated in the invasion of placental villi, degradation of the extracellular matrix, immune tolerance, tumorigenesis and angiogenesis [22,23,45]. Diverse tumors that lose the expression of only one type of MHC class I molecule are able to escape a specific CTL response $[25,46,47]$ but selected IFN- $\gamma$-inducible genes, at least in the murine model, confer target specificity to interrupted immune recognition. When a tumor loses the expression of all MHC class I molecules, it can no longer be recognized by CTLs, although it may become susceptible to the $\mathrm{CD} 56^{\text {bright }} \mathrm{CD} 16$ NK subset [19] (Figure 2). However, tumors that lose only one MHC class I molecule may be able to avoid recognition by specific CTLs while remaining resistant to NK cells, conferring a selective advantage (Figure 2). For instance, hepatic MHC class II expression appears to be necessary to allow the directed killing of pre-malignant hepatocytes as senescence surveillance was significantly impaired in mice with liver specific MHC class II deficiency $[10,11]$. The ultimate immune response may depend on where and when tumor-specific antigens form [31-33]. The senescence surveillance of pre-malignant tumor cells is reportedly orchestrated by antigen-specific $\mathrm{T}$ cells. In the future, cellular senescence program may be induced by reagents or biological materials; the clearance of senescent tumor cells is executed by tumor immune surveillance with the mounting specific immune responses against antigens expressed in induced-senescent cells. Furthermore, use of the senescence program to trigger or enhance antigen-specific immune responses will likely find broad applications to improve vaccination strategies.

\section{Acknowledgements}

We sincerely thank Professor Luc Van Kaer (Vanderbilt University Medical Center). This study was supported in part by grants from the Ministry of Education, Culture, Science and Technology, and The Foundation of Osaka Cancer Research, The Ichiro Kanehara Foundation for the Promotion of Medical Science and Medical Care, The foundation for the Promotion of Cancer Research, The Kanzawa Medical Research Foundation, The Shinshu Medical Foundation and The Takeda Foundation for Medical Science.

\section{References}

1. Zaloudek C, Hendrickson MR (2002) Mesenchymal tumors of the uterus, in Kurman RJ (ed): Blaustein`s Pathology of the Female Genital Tract (ed 5). New York, Springer-Verlag, 561-578

2. Lin JF, Slomovitz BM (2008) Uterine sarcoma. Curr Oncol Rep 10: 512-518.

3. Amant F, Coosemans A, Debiec-Rychter M, Timmerman D, Verquote I (2009) Clinical management of uterine sarcomas. Lancet Oncol 10: 1188-1198.

4. Miettinen M, Fetsch JF (2006) Evaluation of biological potential of smooth muscle tumors. Histopathology 48: 97-105.

5. Brooks SE, Zhan M, Cote T, Baquet CR (2004) Surveillance, epidemiology, and end results analysis of 2677 cases of uterine sarcoma 1989-1999. Gynecol Oncol 93: 204-208. 
Citation: Hayashi T, Horiuchi A, Sano K, Hiraoka N, Ichimura T, et al. (2012) Tumor Immunoediting, from T Cell-Mediated Immune Surveillance to Tumor-Escape of Uterine Leiomyosarcoma. J Vaccines Vaccin S1:002. doi:10.4172/2157-7560.S1-002

Page 5 of 6

6. Dusenbery KE, Potish RA, Judson P (2004) Limitations of adjuvant radiotherapy for uterine sarcomas spread beyond the uterus. Gynecol Oncol 94: 191-196.

7. Wu TI, Chang TC, Hsueh S, Hsu KH, Chou HH, et al. (2006) Prognostic factors and impact of adjuvant chemotherapy for uterine leiomyosarcoma. Gynecol Oncol 100: 166-172.

8. Collado M, Serrano M (2010) Senescence in tumours: evidence from mice and humans. Nature Rev Cancer 10: 51-57.

9. Hanahan D, Weinberg RA (2011) Hallmarks of Cancer: The Next Generation Cell 144: 646-674

10. Serrano M (2011) Cancer: Final act of senescence. Nature 479: 481-482.

11. Kang TW, Yevsa T, Woller N, Hoenicke L, Wuestefeld L, et al. (2011) Senescence surveillance of pre-malignant hepatocytes limits liver cancer development. Nature 479: 547-551.

12. Maniatis T (1999) A ubiquitin ligase complex essential for the NF-kappaB, Wnt/ Wingless, and Hedgehog signaling pathways. Genes Dev 13: 505-510.

13. Groettrup M, Khan S, Schwarz K, Schmidtke G (2001) Interferon-y inducible exchanges of 20 s proteasome active site subunits: why? Biochimie 83: $367-$ 372

14. Nakajima C, Uekusa Y, Iwasaki M, Yamaguchi N, Mukai T, et al. (2001) A role of interferon- $\gamma$ (IFN- $\gamma$ ) in tumor immunity: $T$ cells with the capacity to reject tumor cells are generated but fail to migrate to tumor 11 sites in IFN- $\gamma-d$ mice. Cancer Res 61: 3399-3405.

15. Shankaran V, Ikeda H, Bruce AT, White JM, Swanson PE, et al. (2001) IFNgamma and lymphocytes prevent primary tumor development and shape tumour immunogenicity. Nature 410: 1107-1111.

16. Gaczynska M, Rock KL, Goldberg AL (1993) Gamma-Interferon and expression of MHC genes regulate peptide hydrolysis by proteasomes. Nature 365: 264 267.

17. Delp K, Momburg F, Hilmes C, Huber C, Seliger B (2000) Functional of components of the $\mathrm{MHC}$ class I antigen pathway in human tumors of epithelial origin. Bone Marrow Transplant 26: 88-95.

18. Dunn GP, Bruce AT, Ikeda H, Old LJ, Schreiber RD (2002) Cancer Immunoediting: from immuno- surveillance to tumor escape. Nature Immunol 3: $991-998$.

19. Dunn GP, Old LT, Schreiber RD (2004) The Immunobiology of Cancer Immunosurveillance and Immunoediting. Immunity 21: 137-148.

20. Van Kaer L, Ashton-Rickardt PG, Eichelberger M, Gaczynska M, Nagashima $\mathrm{K}$, et al. (1994) Altered peptidase and $T$ cell response in LMP2 mutant mice. Immunity 1: 533-541.

21. Hayashi T, Faustman DL (2002) Development of spontaneous uterine tumors in low molecular mass polypeptide-2 knockout mice. Cancer Res 62: 24-27.

22. Hayashi T, Horiuchi A, Sano K, Hiraoka N, Kasai M, et al. (2011) Potential role of LMP2 as tumor-suppressor new targets for uterine leiomyosarcoma therapy. Sci Rep 1: 180.

23. Hayashi T, Kobayashi Y, Kohsaka S, Sano K (2006) The mutation in ATP binding region of JAK1, in human uterine leiomyosarcomas, results in defective interferon-gamma inducibility of TAP1 and LMP2. Oncogene 25 : 4016-4026.

24. Wolfers J, Lozier A, Raposo G, Regnault A, Thery C, et al. (2001) Tumorderived exosomes are a source of shared tumor rejection antigens for CTL cross-priming. Nat Med 7: 297-303.

25. Berg L, Danska J, Frelinger J, Perry ME (1997) Manipulation of immune response Janeway, C.A. Travers P. Hunt S. Walport M. eds. . Immunobiology, Immune System in Health and Disease, Garland Publishing Inc. New York: 13-1-13-38.

26. Delp K, Momburg F, Hilmes C, Huber C, Seliger B (2000) Functiona of componen ts of the $\mathrm{MHC}$ class I antigen pathway in human tumors of epithelial origin. Bone Marrow Transplant 25: S88-95.

27. Dovhey SE, Ghosh NS, Wright KL (2000) Loss of interferon-gamma inducibility of TAP1 and LMP2 in a renal cell carcinoma cell line. Cancer Res 60: 57895796.
28. Seliger B, Wollscheid U, Momburg F, Blankenstein T, Huber C (2001) Characterization of the major histocompatibility complex class I ncies in B16 melanoma cells. Cancer Res 61: 1095-1099.

29. Johnsen A, France J, Sy MS, Harding CV (1998) Down-regulation of the transporter for antigen presentation, proteasome subunits, and class I majo histocompatibility complex in tumor cell lines. Cancer Res 58: 3660-3667.

30. Nakajima C, Uekusa Y, Iwasaki M, Yamaguchi N, Mukai T, et al. (2001) A role of interferon-gamma (IFN-gamma) in tumor immunity: T cells with the capacity to reject tumor cells are generated but fail to migrate to tumor sites in IFNmice. Cancer Res 61: 3399-3405

31. Shankaran V, Ikeda H, Bruce AT, White JM, Swanson PE, et al. (2001) IFNgamma and lymphocytes prevent primary tumor development and shape tumour immunogenicity. Nature 410: 1107-1111.

32. Ochsenbein AF, Sierro S, Odermatt B, Pericin M, Karrer U, et al. (2001) Roles of tumour localization, second signals and cross priming in cytotoxic T-cell induction. Nature 411: 1058-1064.

33. Pardoll D (2001) T cells and tumours. Nature 411: 1010-1012.

34. Van Kaer L, Ashton-Rickardt PG, Eichelberger M, Gaczynska M, Nagashima $\mathrm{K}$, et al. (1994) Altered peptidase and

c T cell response in LMP2 mutant mice. Immunity 1: 533-541.

35. Colucci F, Caligiuri MA, Di Santo JP (2003) What does it take to make a natura killer? Nat Rev Immunol 3: 413-425.

36. Freud AG, Caligiuri MA (2006) Human natural killer cell development. Immuno Rev 214: 56-72.

37. Vosshenrich CA, Garcia-Ojeda ME, Samson-Villeger SI, Pasqualetto V, Enault L, et al. (2006) A thymic pathway of mouse natural killer cell development characterized by expression of GATA-3 and CD127. Nat Immunol 7: 1217 1224

38. Hanna J, Mandelboim O (2007) When killers become helpers. Trends Immuno 28: 201-206.

39. Lieberman N, Mandelboim O (2000) The role of NK cells in innate immunity. Adv Exp Med Biol 479: 137-145.

40. Zingoni A, Sornasse T, Cocks BG, Tanaka Y, Santoni A, et al. (2005) NK cell regulation of $T$ cell-mediated responses. Mol Immunol 42: 451-454.

41. Cooper MA, Fehniger TA, Caligiuri MA (2001) The biology of human natura killer-cell subsets. Trends Immunol 22: 633-640.

42. Xue W, Zender L, Miething C, Dickins RA, Hernando E, et al. (2007) Senescence and tumour clearance is triggered by p53 restoration in murine liver carcinomas. Nature 455: 656-660.

43. Zhai YL, Kobayashi Y, Mori A, Orii A, Nikaido T, et al. (1999) Int J Gyneco Pathol 18: 20-28.

44. Leiser AL, Anderson SE, Nonaka D, Chuai S, Olshen AB, et al. (2006) Apoptotic and cell cycle regulatory markers in uterine leiomyosarcoma. Gynecol Oncol 101: 86-91.

45. Wang HX, Wang HM, Li QL, Lin HY, Qian D, et al. (2004) Expression of proteasome subunits low molecular mass Polypeptide (LMP) 2 and LMP7 in the endometrium and placenta of rhesus monkey (Macaca mulatta) during early pregnancy. Biol Reprod 71: 1317-1324.

46. Boon T, Cerottini JC, Van den Eynde B, Van der Bruggen P, Van Pel A (1994) Tumor antigens recognized by T Iymphocytes. Annu Rev Immunol 12: 337-365.

47. Wang RF, Rosenberg SA (1999) Human tumor antigens for cancer vaccine development. Immunol Rev 170: 85-100.

48. Moffett-King A (2002) Natural killer cells and pregnancy. Nat Rev Immunol 9 : 656-663.

49. Yadi H, Burke S, Madeja Z, Hemberger M, Moffett A, et al. ( 2008) Unique receptor repertoire in mouse uterine NK cells. J Immunol 181: 6140-6147.

50. Male V, Hughes T, McClory S, Colucci F, Caligiuri MA, et al. (2010) Immature NK cells, capable of producing IL-22, are present in human uterine mucosa. J Immunol 185: 3913-3918.

51. Ashkar AA, Di Santo JP, Croy BA (2000) Interferon gamma contributes to initiation of uterine vascular decidual integrity, and uterine natura killer cell maturation during normal murine pregnancy. J Exp Med 192: 259-270. 
Citation: Hayashi T, Horiuchi A, Sano K, Hiraoka N, Ichimura T, et al. (2012) Tumor Immunoediting, from T Cell-Mediated Immune Surveillance to Tumor-Escape of Uterine Leiomyosarcoma. J Vaccines Vaccin S1:002. doi:10.4172/2157-7560.S1-002

Page 6 of 6

52. Hanna J, Goldman-Wohl D, Hamani Y, Avraham I, $\quad$ C, et al. (2006) Decidual NK cells regulate key developmental processes at the human fetalmaternal interface. Nat Med 12: 1065-1074.
53. Shi FD, Ljunggren HG, La Cava A, Van Kaer L (2011) Org of natural killer cells. Nat Rev Immunol 11: 658-671. features

This article was originally published in a special issue, Tumor Immunology Vaccines handled by Editor(s). Dr. Robert John Amato, The University of Texas, USA 